\title{
Pesticide residues in milk and their relationship with pesticide contamination of feedstuffs supplied to dairy cattle in Punjab (India)
}

\author{
J.S. Bedi', J.P.S. Gill, P. Kaur and R.S. Aulakh \\ Guru Angad Dev Veterinary and Animal Sciences University, School of Public Health and Zoonoses, \\ Ludhiana, Punnjab-141001, India
}

KEY WORDS: pesticide residues, milk, relationship, concentrates, green fodders, dairy cattle

Received: 10 October 2016

Revised: 3 November 2017

Accepted: 15 January 2018

${ }^{1}$ Corresponding author:

e-mail: bedijasbir78@gmail.com

\begin{abstract}
The aim of the present study was to investigate the correlation between pesticides contamination of feedstuffs supplied to dairy cattle and pesticide residues in bovine milk. The animal concentrate feed, fodder, water and milk samples were collected from 55 dairy farms in Punjab (India) representing intensive production and typical feeding management. The concentrate feed, fodder/silage, water and milk samples were extracted by multiple residue methodology and pesticide residues concentration was estimated by gas chromatography. It was shown that chlorpyrifos pesticide was the main contaminant detected at mean level of $6.01,4.05$ and $2.58 \mathrm{ng} \cdot \mathrm{g}^{-1}$ in concentrate feed, fodder and milk samples, respectively. Other pesticide residues observed in feed and milk samples were: endosulphan sulphate, cypermethrin, ethion, p,p'-DDE, lindane, malathion and fenvalerate. Chlorpyrifos was the only pesticide detected in one water sample. Though the mean residue levels of pesticides were substantially below the maximum residue limits (MRL), individually two milk samples exceeded the MRL value for lindane $\left(1.0 \mathrm{ng} \cdot \mathrm{g}^{-1}\right)$ and three for DDT $\left(20.0 \mathrm{ng} \cdot \mathrm{g}^{-1}\right)$ and chlorpyrifos $\left(20.0 \mathrm{ng} \cdot \mathrm{g}^{-1}\right)$. Two milk samples also violated the MRL value $\left(10.0 \mathrm{ng} \cdot \mathrm{g}^{-1}\right)$ for endosulphan sulphate residues. However, none of the samples was found above the MRL $\left(50.0 \mathrm{ng} \cdot \mathrm{g}^{-1}\right)$ for cypermethrin. The relationship between occurrence of pesticide residues in feedstuff and milk might suggest that animal feed is the main source for appearance of pesticides in milk. However, environmental contamination with pesticides, lack of good management practices while using pesticides and violation of withdrawal period for ectoparasiticides may also result in the occurrence of pesticide residues in milk.
\end{abstract}

\section{Introduction}

The use of pesticides is indispensable to enhance the agricultural production and control vector-borne human and animal diseases. However, the inappropriate use of pesticides may lead to residues in concentrate feeds and fodder supplied to cattle especially when the withdrawal period is not respected
(Rothwell et al., 2001). Also, animals may be exposed to pesticide residues during spraying with pesticide the cattle barn to avoid vector-borne diseases. In time of spraying, the water and feed should be well protected, unless the accidental spills may occur, which may result in feed and water contamination and the further pesticide ingestion by animals (Tsiplakou et al., 2010). Pesticides after entering 
animal body, are metabolized and deposited in fat and muscles. They might be also secreted into the milk. Usually, the presence of pesticide residues in animal feeds is the main source of pesticides in dairy products. Also, the pesticides from the environment can be transferred to milk.

Contamination of milk and dairy products with pesticide residues is a matter of serious public health concern, since they are widely consumed by infants, children and adults (Goulart et al., 2008). This point is of particular interest since young children may be highly exposed to pesticide residues and may be at higher risk of adverse health effects because of their physiological characteristics. Continuous analysing of animal feedstuffs and milk for pesticide residues is indispensable to monitor the levels and identify main sources of milk contamination. Also, the increasing environmental pollution in dairy farms in India needs to be further examined. Moreover, such data can be used to prevent from and control chemical contaminants in milk and dairy products. So, having in mind above facts and considering acute and chronic toxicity effects on human caused by pesticide residues in food, the aim of the study was to analyse the presence of pesticide residues in feedstuffs and water supplied to dairy cattle, as well as in the milk produced at farm level in Punjab, India.

\section{Material and methods}

\section{Chemicals}

All used reagents, chemicals and solvents were of analytical grade and were procured from Merck (Darmstadt, Germany), Rankem - Avantor Performance Materials India Ltd (Gurgaon, India) and SDFine-Chem Ltd (Mumbai, India). Acetone, hexane, acetonitrile were glass distilled before use. Silica gel (60-120 mesh) was purified by washing with dichloromethane and acetone followed by activation at $135^{\circ} \mathrm{C}$ for $3 \mathrm{~h}$. In a similar manner anhydrous sodium sulphate was also washed and activated. Florisil was used as such without any treatment. Analytical technical grade standards with $93-99 \%$ purity for organochlorine pesticides (OCPs: lindane and its isomers, heptachlor, aldrin, fipronil, butachlor, dieldrin, DDT and its metabolites, endrin, $\beta$-endosulphan and endosulphan sulphate), organophosphorus pesticides (OPs: chlorpyrifos, monocrotophos, dimethoate, phorate, fenitrothion, parathion-methyl, malathion, fenamiphos, profenphos, ethion, triazophos and phosalone) and synthetic pyretheroids (SPs: cypermethrin, permethrin, cyfluthrin, cyhalothrin, deltamethrin and fenvalerate) were used to detect the residues of these pesticides in the samples. Pesticide standards were purchased from Sigma-Aldrich (St. Louis, MO, USA).

\section{Sampling}

Punjab is an agricultural state in which animal husbandry is one of major diversified sector. In total 55 dairy farms representing common intensive farming in Punjab were visited and samples of concentrate feed, fresh green fodder and water supplied to animals as well as samples of pooled milk were collected. All the samples were placed in plastic bags and transported in styrofoam boxes with recyclable ice and stored at $-20{ }^{\circ} \mathrm{C}$ until processing. The concentrate feed and fodder samples were collected from the animal sheds. Water samples were collected from water troughs. The raw milk samples were collected directly from the cans/cooling tanks.

\section{Extraction and analyses}

Pesticide residues from milk samples were extracted according to the method of Battu et al. (2004). Briefly, milk sample was mixed thoroughly with activated silica gel and anhydrous sodium sulphate and extracted with dichlormethane and acetone. The collected dichloromethane and acetone extracts were evaporated completely and reconstituted with $3 \mathrm{ml}$ of $n$-hexane. For the extraction of pesticide residues from concentrate feed samples, the method of Mills et al. (1972) with some modifications was adopted using immersion for extraction and florisil for clean-up of the samples. Similarly fodder samples were processed by method of Kang et al. (2002) with suitable modifications. However, water samples were extracted as per the methodology described by Hernandez et al. (1993) with slight modifications using liquid-liquid partiotioning. Reconstituted extract $(1-2 \mu 1)$ was injected into gas chromatograph (GC, model 2010, Shimadzu Corporation, Kyoto, Japan) equipped with electron capture detector for OCPs and SPs detection and flame thermionic detector for OPs detection. (Bedi et al., 2013). Briefly, the capillary column (RTX-5, low polarity phase, $5 \%$ diphenyl $/ 95 \%$ dimethyl polysiloxane) with temperature range from $60{ }^{\circ} \mathrm{C}$ to $350{ }^{\circ} \mathrm{C}$ was used. The oven temperature for $\mathrm{GC}$ analysis of OCPs and SPs was initially programed at temperature of $170^{\circ} \mathrm{C}$ for $13 \mathrm{~min}$ followed by temperature ramp to $270{ }^{\circ} \mathrm{C}$ at the rate of $3{ }^{\circ} \mathrm{C} \cdot \mathrm{min}^{-1}$ (hold time $20 \mathrm{~min}$ ). For GC analysis of OPs initial oven temperature was set at $150{ }^{\circ} \mathrm{C}$ (hold time for $5 \mathrm{~min}$ ) followed by temperature increase to $220^{\circ} \mathrm{C}$ at the rate of $10{ }^{\circ} \mathrm{C} \cdot \mathrm{min}^{-1}$ (hold time for $5 \mathrm{~min}$ ) and final temperature ramped to $250{ }^{\circ} \mathrm{C}$ at a rate of $5^{\circ} \mathrm{C} \cdot \mathrm{min}^{-1}$ (hold time for $13 \mathrm{~min}$ ). The temperature of injection port was set at $280^{\circ} \mathrm{C}$ 
whereas temperature of both detectors was adjusted at $310^{\circ} \mathrm{C}$. Nitrogen was used as carrier gas while hydrogen and air were used for flame formation in flame thermionic detector.

Analyses were identified by comparing the retention times and peak height/area with the reference standards run under similar operating conditions The confirmation of pesticide residues was done by GC-Mass Spectrometer (GC-MS model QP2010 plus, Shimadzu Corporation, Kyoto, Japan) in which a characteristic mass spectrum was obtained based on mass-charge ratio of a compound (Bedi et al., 2013). Briefly, the oven temperature was initially set at $80^{\circ} \mathrm{C}$ followed by increase to $280^{\circ} \mathrm{C}$. The mass spectrometer was operated in electron ionization mode. The interface, manifold and ion source temperatures were maintained at 290, 50, and $200{ }^{\circ} \mathrm{C}$, respectively. The emission current for the ionization filament was set at $80 \mathrm{~A}$ generating electrons with energy of $70 \mathrm{eV}$. Helium $(99.99 \%)$ at a flow rate of $0.94 \mathrm{ml} \cdot \mathrm{min}^{-1}$ was used as carrier.
The reagent and sample blank were extracted and analysed in triplicate to negate the false peaks in common. The trueness of the method used for extraction and estimation was validated by the processing of spiked fish, sediments and water samples with standard pesticides at concentrations of 10,20 and $50 \mathrm{ng} \cdot \mathrm{g}^{-1}$. The mean recovery values of spiked samples were ranged from $78.3 \%$ for deltamethrin to $89.4 \%$ for aldrin, which was in accordance with the acceptable recovery range of $70-120 \%$ (Fajgelj and Ambrus, 2000). Repeatability of the method was aligned in accordance with the recommendations concerning relative standard deviation of the recoveries values below 10\% (Fajgelj and Ambrus, 2000). The calculated concentrations of residues in samples were not corrected for recovery. The limit of detections were calculated from the detector response using a signal:noise ratio of 3 and the values were varied from 0.3 to $4.0 \mathrm{ng} \cdot \mathrm{g}^{-1}$ for OCPs, $1.0-8.0 \mathrm{ng} \cdot \mathrm{g}^{-1}$ for SPs and 3.5-13 $\mathrm{ng} \cdot \mathrm{g}^{-1}$ for OPs.

Table 1. Concentration of pesticide residues detected in concentrate feed, fodder, water and milk samples from Punjab (India) and parameters of correlation between total pesticide residues in feed and water, and pesticide residues in milk

\begin{tabular}{|c|c|c|c|c|c|c|c|}
\hline \multirow[b]{2}{*}{ Pesticides } & \multicolumn{5}{|c|}{ Pesticides concentration in, $\mathrm{ng} \cdot \mathrm{g}^{-1}$} & \multicolumn{2}{|c|}{ Correlation } \\
\hline & $\begin{array}{l}\text { concentrate } \\
\text { feed }\end{array}$ & green fodder & water & $\begin{array}{l}\operatorname{sum}^{1} \\
(Y)\end{array}$ & $\begin{array}{l}\text { milk } \\
(X)\end{array}$ & $\begin{array}{l}r \\
(X Y)\end{array}$ & $P$-value \\
\hline Lindane & $\begin{array}{l}2.73 \pm 10.11 \\
(N D-48.7) \\
4\end{array}$ & ND & ND & $\begin{array}{l}2.73 \pm 10.11 \\
(N D-48.7) \\
4\end{array}$ & $\begin{array}{r}0.46 \pm 2.58 \\
2^{(N D-17.8)}\end{array}$ & 0.59 & 0.001 \\
\hline DDT & $\begin{array}{l}1.90 \pm 8.34 \\
3^{(N D-45.2)}\end{array}$ & ND & ND & $\begin{array}{r}1.90 \pm 8.34 \\
3^{(N D-45.2)}\end{array}$ & $\begin{array}{l}0.83 \pm 3.71 \\
3^{(N D-22.8)}\end{array}$ & 0.23 & 0.092 \\
\hline Endosulphan sulphate & $\begin{array}{l}2.95 \pm 8.64 \\
6 \\
6\end{array}$ & $\begin{array}{l}2.80 \pm 9.19 \\
5 \\
5\end{array}$ & ND & $\begin{array}{l}5.75 \pm 15.84 \\
7 \\
7\end{array}$ & $\begin{array}{l}1.01 \pm 4.07 \\
4\end{array}$ & 0.764 & 0.001 \\
\hline Cypermethrin & $\begin{array}{l}3.48 \pm 11.52 \\
{ }_{5}^{(N D-49.1)}\end{array}$ & $\begin{array}{l}3.03 \pm 11.60 \\
(\mathrm{ND}-64.4)\end{array}$ & ND & $\begin{array}{l}6.51 \pm 18.58 \\
7 \\
7^{(N D-96.8)}\end{array}$ & $\begin{array}{l}2.21 \pm 7.85 \\
5 \\
5\end{array}$ & 0.42 & 0.001 \\
\hline Fenvalerate & $\begin{array}{l}2.62 \pm 9.59 \\
3^{(N D-50.2)}\end{array}$ & ND & ND & $\begin{array}{l}2.62 \pm 9.59 \\
3^{(N D-50.2)}\end{array}$ & $\begin{array}{r}1.40 \pm 6.06 \\
2^{(N D-34.5)}\end{array}$ & -0.064 & 0.641 \\
\hline Chlorpyrifos & $\begin{array}{l}6.01 \pm 13.64 \\
(\mathrm{ND}-61.2) \\
10\end{array}$ & $\begin{array}{l}4.05 \pm 12.06 \\
(\mathrm{ND}-49.5) \\
6\end{array}$ & $\begin{array}{l}0.35 \pm 2.63 \\
1^{(N D-19.5)}\end{array}$ & $\begin{array}{l}10.23 \pm 20.60 \\
12^{(N D-78.4)}\end{array}$ & $\begin{array}{l}2.58 \pm 8.11 \\
6 \\
6\end{array}$ & 0.435 & 0.001 \\
\hline Ethion & $\begin{array}{l}3.77 \pm 11.3 \\
{ }_{5}^{(N D-39.5)}\end{array}$ & ND & ND & $\begin{array}{l}3.77 \pm 11.3 \\
5 \\
5\end{array}$ & $\begin{array}{r}0.94 \pm 4.12 \\
3^{(N D-42.5)}\end{array}$ & 0.146 & 0.289 \\
\hline Malathion & 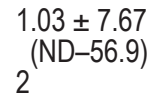 & ND & ND & $\begin{array}{l}1.03 \pm 7.67 \\
2^{(N D-56.9)}\end{array}$ & $\begin{array}{l}0.63 \pm 4.67 \\
{ }_{1}^{(N D-34.6)}\end{array}$ & 1.0 & 0.001 \\
\hline Cyhalothrin & $\begin{array}{l}2.20 \pm 8.73 \\
3^{(N D-47.1)}\end{array}$ & $\begin{array}{l}1.85 \pm 7.90 \\
3^{(N D-41.5)}\end{array}$ & ND & $\begin{array}{l}4.05 \pm 11.40 \\
(\mathrm{ND}-47.1) \\
6\end{array}$ & ND & - & - \\
\hline Profenofos & $\begin{array}{r}2.31 \pm 8.93 \\
2^{(N D-54.5)}\end{array}$ & & ND & $\begin{array}{l}2.31 \pm 8.93 \\
2^{(N D-54.5)}\end{array}$ & ND & - & - \\
\hline Deltamethrin & ND & $\begin{array}{r}0.63 \pm 4.65 \\
(\mathrm{ND}-34.6) \\
1\end{array}$ & ND & $\begin{array}{l}0.63 \pm 4.65 \\
(\mathrm{ND}-34.6)\end{array}$ & ND & - & - \\
\hline
\end{tabular}

${ }^{1}$ total concentration of pesticide in concentrate feed, fodder and water; ND - not detected; $r$ - correlation coefficient; data of pesticide concentration are presented as: mean \pm standard deviation, range of values and the number of positive samples 
The results are expressed in arithmetic mean value of pesticide residues with unit of $\mathrm{ng} \cdot \mathrm{g}^{-1}$ on wet weight basis. While calculation of mean value, the levels of negative samples were considered as zero. Pearson correlation was calculated between presences of pesticide residues in milk and the total concentration of pesticide in feed and water. The measurements were considered to be statistically significant at $P<0.05$.

\section{Results}

The analysis of concentrate feed, green fodder and milk samples collected from animal farms indicated the presence of OCPs, OPs and SPs residues (Table 1).

In the concentrated feed samples the percentage proportion reflected highest share of OPs (45.3\%) followed by SPs (28.5\%) and OCPs (26.2\%) (Figure 1A). Further, in OPs, chlorpyrifos contributed maximum (45.7\%) while cypermethrin (42.1\%) and endosulphan sulphate (38.9\%) shared utmost among SPs and OCPs groups, respectively. Mean residue levels of chlorpyrifos and endosulphan sulphate were $6.01 \mathrm{ng} \cdot \mathrm{g}^{-1}$ and $2.95 \mathrm{ng} \cdot \mathrm{g}^{-1}$, respectively. Similarly, in green fodder samples collected from different farms SPs was detected utmost with percentage proportion of $44.6 \%$ followed by OPs $(32.8 \%)$ and
OCPs (22.7\%) (Figure 1B). Only one water sample was contaminated with chlorpyrifos residues.

Among all pesticide residues detected in milk, the main contaminant was chlorpyrifos, recorded in 6 out of $55(10.1 \%)$ samples, followed by cypermethrin $(9.1 \%)$, endosulphan sulphate $(7.3 \%)$, p,p'-DDE (5.4\%), ethion (5.4\%), lindane $(3.6 \%)$, fenvalerate $(3.6 \%)$ and malathion $(1.85 \%)$. The proportion of pesticide residues groups detected in milk samples indicated the highest contribution of OPs (41.2\%) followed by SPs (35.9\%) and OCPs (22.9\%) (Figure 1C). The mean residue levels of pesticides were found to be lower than the maximum residue limits (MRL) fixed by FAO/WHO Codex Alimentarius (FAO/WHO, 2016) and Food Safety and Standard Authority of India (FSSAI, 2011). However, two pool milk samples exceeded the MRL values for lindane $\left(1.0 \mathrm{ng} \cdot \mathrm{g}^{-1}\right)$, and three for DDT (20.0 $\mathrm{ng} \cdot \mathrm{g}^{-1}$ ) and chlorpyrifos (20.0 $\mathrm{ng} \cdot \mathrm{g}^{-1}$ ). Two milk samples also violated the MRL value $\left(10.0 \mathrm{ng} \cdot \mathrm{g}^{-1}\right)$ for endosulphan sulphate residues. However, none of the samples was found above the MRL (50.0 $\mathrm{ng} \cdot \mathrm{g}^{-1}$ ) for cypermethrin.

The conformation of pesticide residues detected on GC revealed their conformation on GC-MS by matching the retention times and fragmented ion patterns (Figure 2).

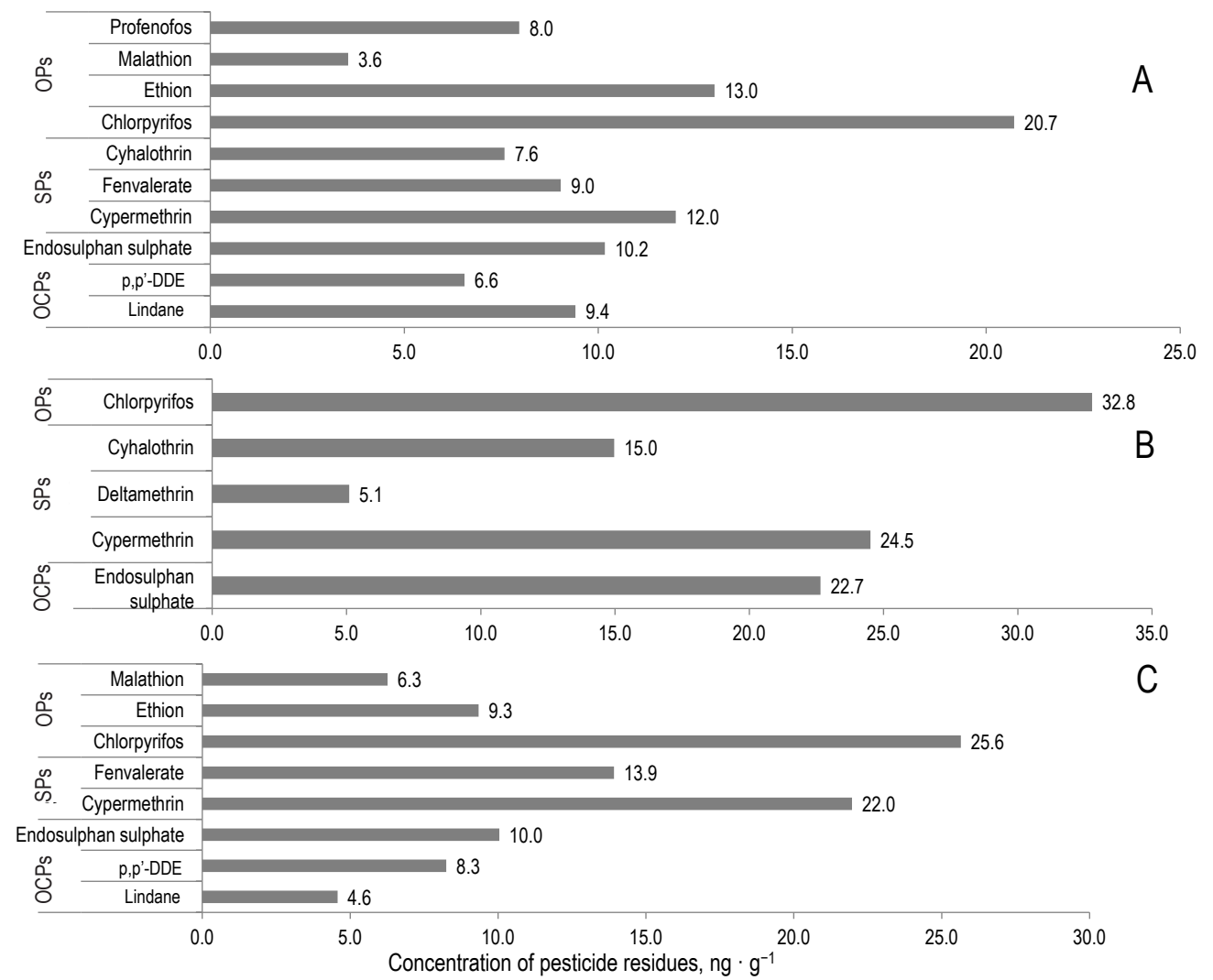

Figure 1. Percentage proportion of organochlorine pesticides (OCPs), synthetic pyretheroids (SPs) and organophosphorus pesticides (OPs) residues detected in the concentrate feed $(A)$, fodder $(B)$ and milk $(C)$ samples 

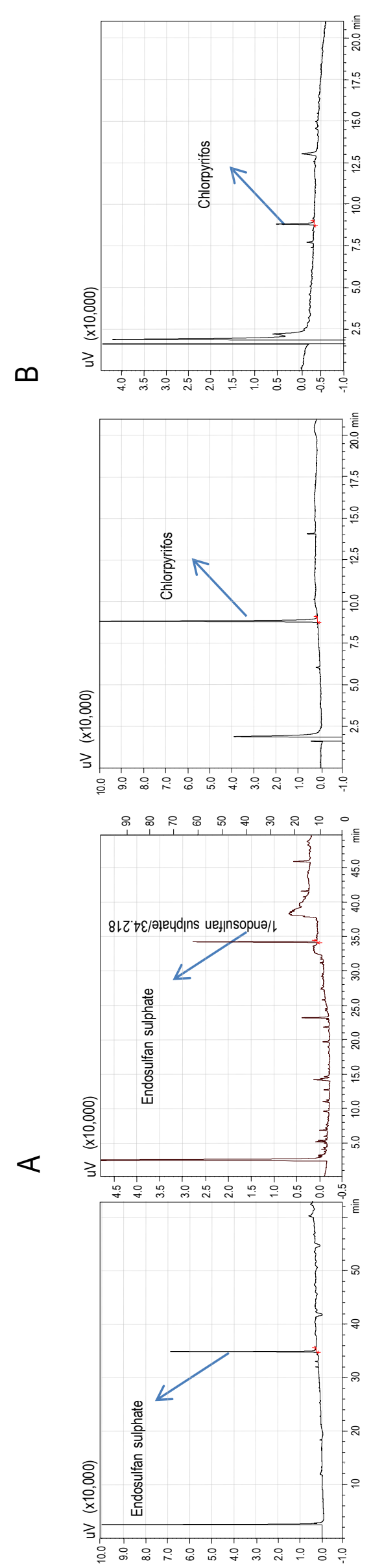

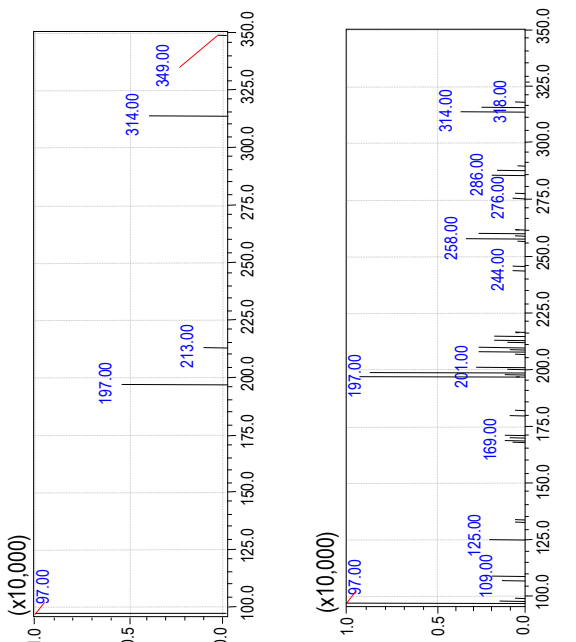

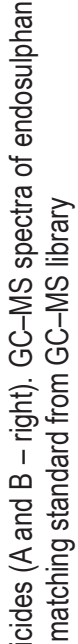

这

罗 능

家

喜

焉

ㅇㅇㄹ

응

등

홍

임

选

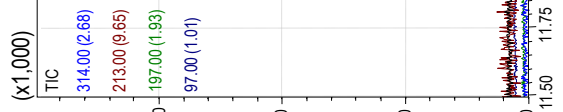

힝

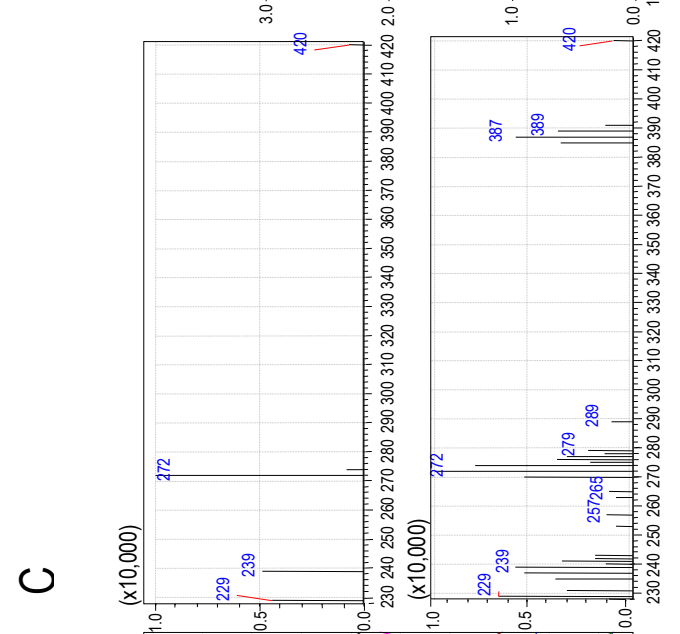

需贾

$1 \%$

을 응

흐응

is

잉

들 을

क्ष

on

온 흔

을 흥

흠

宅

\%

뜽

言

든

홍

음

늠

o 을

등

홍흠

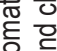

บ을

竞产 


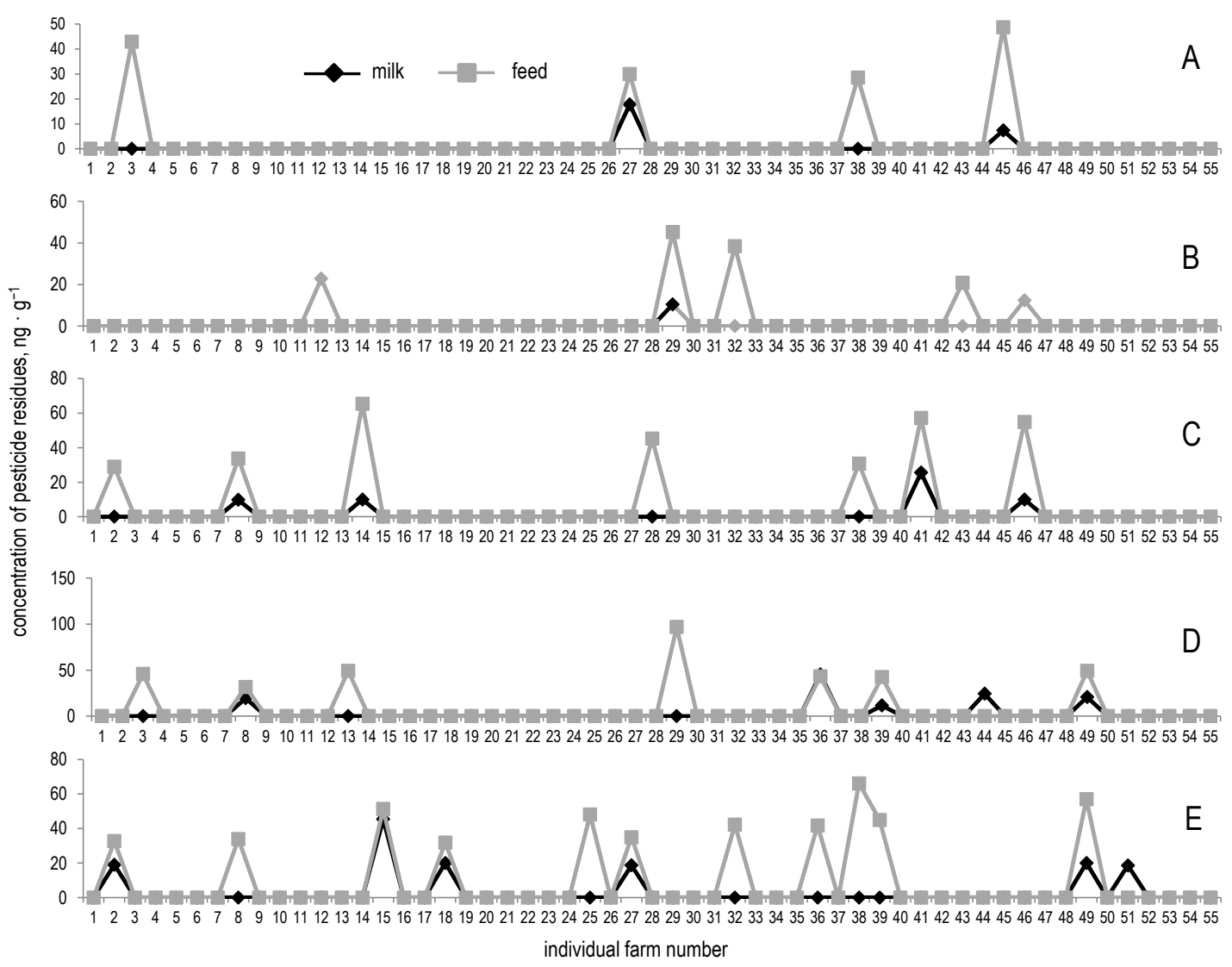

Figure 3. The individual dairy farms results of the selected pesticide residues: lindane (A), p,p'-DDE (B), endosulfan sulphate (C), cypermethrin (D) and chlorpyrifos (E) concentrations in water and feed (presented as sum of pesticide content in concentrate feed, fodder and water), and in milk

Relationship between presence of pesticide residues in animal feedstuffs (feed, fodder and water) and milk was evaluated in terms of correlation coefficients and the values ranged from -0.064 to 1.0 for fenvalerate and malathion, respectively. Statistically significant relationship $(P<0.05)$ was observed for lindane, endosulphan sulphate, chlorpyrifos and malathion residues in milk with the total dietary intake by the animals with value of $r=0.590,0.595,0.614$ and 1.0 , respectively (Table 1). Out of 55 farms, at 12 sites residues of lindane, $p, p$ '-DDE, endosulphan sulphate, cypermethrin and chlorpyrifos (Figure 3A, 3B, 3C, $3 \mathrm{D}, 3 \mathrm{E})$ were detected in both animal concentrate feed and milk samples, while in other farms pesticide residues were only detected either in feed or milk.

\section{Discussion}

In the previous studies the predominance of OCPs viz. DDT metabolites (p,p'-DDE, p,p'-DDT) and lindane in milk samples was evident (Battu et al., 2004; Sharma et al. 2007). This may be related to the imposition of ban/restriction on use of DDT and technical hexachlorocyclohexane $(\mathrm{HCH})$ $(\alpha-, \beta-, \gamma$ - and $\delta$-isomers) and increasing use of OPs and SPs groups as a replacement for persistent OCPs (Government of India, Ministry of Agriculture \& Farmers Welfare, 2015) which is indicated by the occurrence of OPs and SPs even in human breast milk (Feo et al., 2012; Bedi et al., 2013). Similarly, the presence of OPs residues in bovine milk has already been reported by Pagliuca et al. (2006) and Bedi et al. (2015) and is mainly attributed to the ability of OPs to covalently link with milk proteins. Cheema et al. (2004) have also reported the presence of chlorpyrifos in $6.7 \%$ of milk samples collected from Punjab (India), and concentrations in all of these samples exceeded MRL values. In some previous reports from India, animal concentrate feed samples were found to be positive for endosulphan sulphate, chlorpyrifos, phorate, monocrotofos, dimethoate, diazinon, carbaryl p,p'-DDE and p,p'DDT isomers residues (Sharma et al., 2005; Nag and Raikwar, 2011).

Though, the present study was not a controlled feeding experiment and pesticide daily intake was not constant, even then, in $21.8 \%(12 / 55)$ dairy farms the same active compound was detected in 
milk and feedstuff. It suggests that the pesticides residues could have been transferred from animal feed to milk. However, residues of cyhalothrin, profenophos and deltamethrin were detected in animal feed and fodder samples but not noticed in any milk samples. It can be attributed to high solubility of some of these components. Therefore, animals secrete most of these chemicals in their urine and faeces (International Dairy Federation, 1997). On the contrary, at some dairy farms milk samples were found positive for the pesticides, but in foodstuffs these contaminants were not detected. This can be explained by several reasons: pesticide residues in feed could be degraded or below the detection limit, the contaminated feed component was no more present in the farm or it is possible that contamination could result from the use of ectoparasite treatment on animals. Further, the transfer of pesticides from animal feed to milk is influenced by by ingestion, absorption, metabolism and excretion by the lactating animals. The presence of pesticide residues only in water samples may be related with the facts that pesticides residues in water systems can be hardly detected, as they suffer dilution effects, hydrolysis and photolysis on superficial waters. But still, some researchers were able to found high levels in aquatic environment (García de Llasera and BernalGonzález, 2001; Sankararamakrishnan et al., 2005).

Also pesticides (malathion, delatmethrin, cypermethrin, dimetohate, cyfluthrin, cyhalothrin, permethrin, amitraj etc.) were used in some dairy farms to protect the animals from house flies and ticks. Some farmers were facing pesticide resistance problem in vector control which is also reflected by Singh et al. (2014) in the region of present study. Additionally, in some farms that pesticide containers were kept in animal feed storage sites which may result into accidental spillage on feed. Moreover, while spraying pesticides on crops adjacent to dairy farms, the drift and volatilization of these pesticides may result in their deposition on the non-target sites which may include feed, fodder and water. This observation may be related with some findings in India in which residues of DDT, $\mathrm{HCH}$, endosulphan sulphate, chlordanes were detected in air samples from rural and urban environment (Chakraborty et al., 2010; Devi et al., 2011). Similarly, Srimurali et al. (2015) conducted passive air sampling in urban, suburban, coastal, and agriculture areas in Tamil Nadu (Southern India) and found the total concentration of 13 OCPs ranged from not detected to $41400 \mathrm{pg} \cdot \mathrm{m}^{-3}$. DDTs, DDD, heptachlor and mirex were predominant during monsoon season.
As the milk and dairy products are widely consumed by infants, children and adults the pesticide risk management should be introduced in order to prevent the exposure to pesticides either through feed or from the environment, as well as the follow up of a withdrawal time (Kan and Meijer, 2007). Therefore, available pesticide monitory studies are useful to control the levels and identify the main sources of milk and dairy products contamination. Furthermore, the presented data can be used to prevent from and control chemical contaminants in milk and dairy products.

\section{Conclusions}

Milk, animal feed and water samples from dairy farms of the Punjab were found contaminated by organochlorine pesticides (OCPs), synthetic pyretheroids (SPs) and organophosphorus pesticides $(\mathrm{OPs})$ residues. Despite the fact that milk samples were contaminated with pesticide residues, the mean contamination level was lower than maximum residue limits. Though pesticide containing feed is primarily responsible for the pesticide transfer to milk, poor management practices at the farm level while using pesticides may also serve as source of milk contamination. Therefore it is necessary to monitor the milk as well as feeds and fodder destined for animal consumption regularly.

\section{Acknowledgement}

This work was supported by research grants from GADVASU. We thank dairy farmers of Punjab for participating in this study and providing the samples.

\section{References}

Battu R.S., Singh B., Kang B.K., 2004. Contamination of liquid milk and butter with pesticide residues in the Ludhiana district of Punjab state, India. Ecotox. Environ. Safe. 59, 324-331, https://doi.org/10.1016/j.ecoenv.2003.08.017

Bedi J.S., Gill J.P.S., Aulakh R.S., Kaur P., Sharma A., Pooni P.A., 2013. Pesticide residues in human breast milk: Risk assessment for infants in the Punjab, India. Sci. Total Environ. 463-464, 720-726, https://doi.org/10.1016/j.scitotenv.2013.06.066

Bedi J.S., Gill J.P.S., Aulakh R.S., Kaur P., 2015. Pesticide residues in bovine milk in Punjab, India: Spatial variation and risk assessment to human health. Arch. Environ. Contam. Toxicol. 69, 230-240, https://doi.org/10.1007/s00244-015-0163-6

Cheema H.K., Kang B.K., Singh B., 2004. Monitoring of $\mathrm{HCH}$ residues in bovine milk in Punjab, India. Indian J. Environ. Toxicol. 14, 54-58

Chakraborty P., Zhang G., Li J., Xu Y., Liu X., Tanabe S., Jones K.C., 2010. Selected organochlorine pesticides in the atmosphere of major Indian cities: levels, regional versus local variations, and sources. Environ. Sci. Technol. 44, 8038-8043, https:// doi.org/10.1021/es102029t 
Devi N.L., Qi S., Chakraborty P., Zhang G., Yadav I.C., 2011. Passive air sampling of organochlorine pesticides in a northeastern state of India, Manipur. J. Environ. Sci. 23, 808-815, https:// doi.org/10.1016/S1001-0742(10)60453-6

Fajgelj A., Ambrus A., 2000. Guidelines for single-laboratory validation of analytical methods for trace level concentrations of organic chemicals. In: A. Fajgelj., A. Ambrus (Editors). Principles and Practices of Method Validation. Royal Society of Chemistry. Cambridge (UK), https://doi.org/10.1039/978184755175700179

FAO/WHO, 2016. Codex Pesticides Residues in Food Online Database. Codex Alimentarius Commission, FAO and WHO. Rome (Italy), available at: http://www.fao.org/fao-who-codexalimentarius/codex-texts/dbs/pestres/en/

Feo M.L., Eljarrat E., Manaca M.N., Dobaño C., Barcelo D., Sunyer J., Alonso P.L., Menendez C., Grimalt J.O., 2012. Pyrethroid use-malaria control and individual applications by households for other pests and home garden use. Environ. Int. 38, 67-72, https://doi.org/10.1016/j.envint.2011.08.008

FSSAI (Food Safety and Standard Authority of India), 2011. Food Safety and Standards (Contaminants, Toxins And Residues) Regulations, 2011, available at: http://fssai.gov.in/dam/ jcr:755c6420-a74b-44f4-9301-4ddd289b23fc/Contaminants_ Regulations.pdf

García de Llasera M.P., Bernal-González M., 2001. Presence of carbamate pesticides in environmental waters from the northwest of Mexico: determination by liquid chromatography. Water Res. 35, 1933-1940, https://doi.org/10.1016/S00431354(00)00478-4

Goulart S.M., de Queiroz M.E.L.R., Neves A.A., de Queiroz J.H., 2008. Low-temperature clean-up method for the determination of pyrethroids in milk using gas chromatography with electron capture detection. Talanta 75, 1320-1323, https:// doi.org/10.1016/j.talanta.2008.01.058

Government of India, Ministry of Agriculture \& Farmers Welfare, 2015. Statistical Database: Production of Key Pesticides during 2010-11 to 2015-16. Available at: http://ppqs.gov.in/statisticaldatabase/production-key-pesticides-during-2010-11-2015-16

Hernandez F., Beltran J., Sancho J.V., 1993. Study of multi-residue methods for the determination of selected pesticides in groundwater. Sci. Total. Environ. 132, 297-312, https://doi. org/10.1016/0048-9697(93)90139-W

International Dairy Federation (IDF), 1997. Residues and Contaminants in Milk and Milk Products. Ref. S.I. 9701. IDF. Brussels (Belgium)

Kan C.A., Meijer G.A.L., 2007. The risk of contamination of food with toxic substances present in animal feed. Anim. Feed. Sci. Technol. 133, 84-108, https://doi.org/10.1016/j.anifeedsci.2006.08.005
Kang B.K., Singh B., Chahal K.K., Battu R.S., 2002. Contamination of feed concentrate and green fodder with pesticide residues. Pest. Res. J. 14, 308-312

Mills P.A., Bong B.A., Kamps L.R., Burke J.A., 1972. Elution solvent system for Florisil column cleanup in organochlorine pesticide residue analyses. J. Assoc. Off. Anal. Chem. 55, 39-43

Nag S.K., Raikwar M.K., 2011. Persistent organochlorine pesticide residues in animal feed. Environ. Monit. Assess. 174, 327335, https://doi.org/10.1007/s10661-010-1460-1

Pagliuca G., Serraino A., Gazzotti T., Zironi E., Borsari A., Rosmini R., 2006. Organophosphorus pesticides residues in Italian raw milk. J. Dairy. Res. 73, 340-344, https://doi.org/10.1017/ S0022029906001695

Rothwell J.T., Burnett T.J., Hacket K., Chevis R., Lowe L.B., 2001. Residues of zeta-cypermethrin in bovine tissues and milk following pour-on and spray application. Pest Manag. Sci. 57, 993-999, https://doi.org/10.1002/ps.372

Sankararamakrishnan N., Sharma A.K., Sanghi R., 2005. Organochlorine and organophosphorous pesticide residues in ground water and surface waters of Kanpur, Uttar Pradesh, India. Environ. Int. 31, 113-120, https://doi.org/10.1016/j.envint.2004.08.001

Sharma V., Wadhwa B.K., Stan H.J., 2005. Multiresidue analysis of pesticides in animal feed concentrate. Bull. Environ. Contam. Toxicol. 74, 342-349, https://doi.org/10.1007/s00128-0040590-y

Sharma H.R., Kaushik A., Kaushik C.P., 2007. Pesticide residues in bovine milk from a predominantly agricultural state of Haryan, India. Environ. Monit. Assess. 129, 349-357, https://doi. org/10.1007/s10661-006-9368-5

Singh N.K., Jyoti, Haque M., Singh H., Rath S.S., Ghosh S., 2014. A comparative study on cypermethrin resistance in Rhipicephalus (Boophilus) microplus and Hyalomma anatolicum from Punjab (India). Ticks Tick-Borne Dis. 5, 90-94, https://doi. org/10.1016/j.ttbdis.2013.08.002

Srimurali S., Govindaraj S., Kumar S.K., Rajendran R.B., 2015. Distribution of organochlorine pesticides in atmospheric air of Tamilnadu, southern India. Int. J. Environ. Sci. Technol. 12, 1957-1964, https://doi.org/10.1007/s13762-014-0558-3

Tsiplakou E., Anagnostopoulos C.J., Liapis K., Haroutounian S.A., Zervas G., 2010. Pesticides residues in milks and feedstuff of farm animals drawn from Greece. Chemosphere 80, 504-512, https://doi.org/10.1016/j.chemosphere.2010.04.069 